\title{
From competition to collaboration: Unraveling teachers' lesson study experiences
}

\author{
Romiro G. Bautista ${ }^{1}$, Wilfredo B. Baniqued ${ }^{2}$ \\ ${ }^{1}$ College of Teacher Education, Quirino State University-Main Campus, Philippines \\ ${ }^{2}$ College of Engineering, Quirino State University-Cabarroguis Campus, Philippines
}

\section{Article Info \\ Article history: \\ Received Oct 6, 2020 \\ Revised Jun 15, 2021 \\ Accepted Jul 12, 2021}

\section{Keywords:}

Instructional planning

Lesson study

Professional development

program

Research lesson

\begin{abstract}
Lesson study is a professional development program among teachers. It reciprocates teachers' development to students' outcomes. It is also an act of leveraging classroom practices, enriching teachers' content knowledge, and process skills and beliefs. This study explored the experiences of a group of science secondary school teachers that implemented the lesson study in their classes. Qualitative data were gathered from the informants' interview during the implementation of the lesson study. Data were processed through document trail among the informants to ascertain the veracity of the transcribed responses, reflections, and observations. Thematic analysis revealed five themes on the experiences of the teachers in implementing the Lesson Study: developing a culture of oneness, crafting teachers' competence through synergism, boosting teachers' morale and confidence, refining the quality of the research lesson, and scheming avenues for critical thinking. It is, therefore, suggested that lesson study be implemented by all teachers across all subject-areas in the division and introduced among preservice teachers to further discover its efficacy towards teachers' development and students' outcomes. Furthermore, it is strongly suggested that knowledgeable others be involved in the implementation of the lesson study as their presence were found significant in ensuring its success as most of the teachers are not specialized in the field that they are teaching.
\end{abstract}

This is an open access article under the CC BY-SA license.

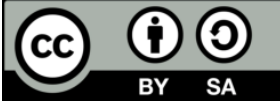

\section{Corresponding Author:}

Romiro G. Bautista

Office of the University Director for Instruction

Quirino State University-Main Campus

3411 Diffun, Quirino, Philippines

Email: romiro.bautista@qsu.edu.ph

\section{INTRODUCTION}

Lesson study, as conceived in Japan and stemmed throughout the world, is a professional development program geared towards developing a culture of inquiry in every classroom instruction. It centers the ideas on renewing classroom practices, enriching teachers' content knowledge and process skills and beliefs; thus, improving students' outcomes that emphasizes social interaction among them [1]-[3]. This professional development program revitalizes instructional planning procedures that reciprocate teachers' development vis-à-vis students' outcomes [3]-[10].

Lesson study (LS), as a professional practice, covers a four-phase cycle: 1) Goal setting and planning: Teacher-implementers meet and collegially make research lesson (RL) for implementation based on the curriculum, unit goal, and competency standards of the subject;2) Teaching the research lesson: one of the teacher-implementers executes the RL in the presence of the members of the group. It must be noted that this is an RL implementation and evaluation and not a demonstration class. The observation centers on 
how the lesson was executed and how the student-learners respond to the RL. The quality of the detailed observations on the students' actual responses must be well-documented as it will orchestrate the measures and revisions to be made in the RL; 3) Post-lesson discussion: This post-lesson discussion is done in a debriefing session where the observations are analyzed. Suggestions and recommendations are sought to further improve the RL; and 4) Consolidation of learning: Recommendations are incorporated in the RL for the next implementation. Revision forms an integral part in the development of the RL. Usually, the group is composed of 3-5 member teachers who are teaching similar fields under the supervision of a senior or a seasoned teacher in a specified field of learning [3], [10], [11]. The implementation of LS in Japan yielded significant results and earned positive feedback in the academic communities around the world [7], [12]-[14]. Aptly, Philippines is one of the countries that looked into the potentialities of conducting LS. The same framework as implemented in Japan and the rest of the world was used by the Philippines in its quest of adopting LS towards leveraging the academic activities and experiences of Filipino students [15], [16].

Aptly, LS in a Division of the Department of Education, Philippines was first implemented in 2017 by the National Institute for Science and Mathematics Education Development, University of the PhilippinesDiliman in coordination with a Provincial Government unit, a State University, and other stakeholders. It started with a Professional Development Training on April 2017 which was participated in by Science and Math teachers in a DepEd-Division, Philippines and professors of a State University who eventually served as knowledgeable others (KOs) of the LS implementations sometime in September 2017 and February 2018. In the Philippines, it is a fact that teachers teach subjects beyond their field of specializations especially in the present educational climate and framework - the Spiral Curriculum. In science, teachers are tasked to teach all branches of science the whole year round despite their academic preparations, i.e., Grade 7-10 science teachers teach Earth Science, Biology, Chemistry, and Physics although these are not their fields of specialization; hence, there is a need to have somebody to facilitate their instructional planning activities as they are not experts in the fields that they are teaching.

The crux is: LS responds to both teachers' development and students' outcomes. Teachers come into an encounter with other teachers from other institutions which serves as an indirect learning for them through focused group discussion (FGD), dialogical interactions, and buzz sessions - all of which are geared towards improving the teaching-and-learning measures under collegial-social reconstruction. Students' outcomes, on the other hand, are an observable outcome of the educational encounter of these LS teacher-implementers in a form of a practiced community of inquiry.

This study tries to mend the gap on providing a bar-none Continuing Professional Developmental (CPD) Program among public schools' teachers in the Philippines particularly in the locale of the study brought by the implementation of the so-called 'spiral curriculum' of the Philippine K-12 program. Let it be noted the Japan's LS is implemented to a group of teachers who are authorities in their field while in the current study, the teachers doing the LS are not authorities in the field that they are trying to teach.

Moreover, this study tries to document evidences on the learnings and experiences of a certain group of teachers as a way of analyzing the benefits earned by the informants since the education sector in the Philippines is trying to adopt LS which is popularized in Japan. Moreover, it tries to gather recommendations on the possibility of incorporating it in the Teacher Education curriculum.

\section{RESEARCH METHOD}

This study employed the Qualitative Research Design using Phenomenology as strategy for inquiry. The informants, where qualitative data were generated, are science teachers who attended the Professional Development Training in LS and members of a science group that implemented RL.

To be qualified as informants of the study, they must have attended the Professional Development Training on implementing Lesson Study at the UP-NISMED and active members of the RL group. Active members are teachers who religiously participated the planning, implementation, and revision of the RL. The informants explained their experiences including a configured mode of understanding and principles - the meanings of their stories and experiences as part of an identity development [17].

One of the proponents personally interviewed the informants to gather the needed data in the study. Before the interview was conducted, the interviewer briefed the informants that their participation in the interview is voluntary and they can terminate it anytime. A consent form was signed by the informants. Transcripts of the interview were carefully transcribed and coded which were validated by a researcher whose credibility is beyond compare. Audit trail was employed in routing the transcripts of the interview to the informants in ascertaining the veracity of the claims. Audit trail is an in-depth approach to illustrating that the transcripts are based on the participants' narratives. It also involved a description on how the data were gathered and analyzed [18], [19]. Henceforth, the data are considered verified and valid. 
Moreover, the gathered data were analyzed through NVIVO qualitative textual analysis software. On the basis of the foregoing, NVIVO is an approach in qualitative data analysis that systematically and rigorously synthesizing unequivocal qualitative data into curated and connected findings in a thematic framework of analysis and presentation [20], [21]. The presented themes in the succeeding section were formulated according to the word cloud from the informants as suggested by the NVIVO results which served as bases in an inquiry-based analysis vis-à-vis the research problem. Aptly, the analysis done in the research includes familiarization and organization, coding and recoding, and summarizing and interpreting $[22]$.

\section{RESULTS AND DISCUSSION}

The following themes were formulated based on the gathered data from the informants' interview. The themes were based on the word cloud output of NVIVO qualitative textual analysis software.

\subsection{Developing a culture of oneness}

The LS implementation in a DepEd-Division, Philippines has developed a culture of oneness among the teacher-implementers particularly on sharing their resources. It can be noted that public schools have limited resources like science facilities and equipment including some consumable materials in the laboratory. In the LS implementation, teachers came to a plan with everybody's share in order to maximize the potential of the lesson. This culture when nurtured will realize a bigger sense of accountability among them. It was claimed that undergoing LS is not just simply undergoing any professional development program but participants are able to develop a shared professional culture through collective participation and long-term perspectives of helping others [15], [16], [23]-[25].

The following transcripts from the informants qualify the claim of this study that LS develops a culture of oneness among them:

Teacher A: “...It fosters sharing of resources between and among teacher-implementers as we have poor laboratory holdings, equipment, and facilities. So, we borrow from other schools that hold those resources, e.g., chemicals, apparatus, etc...

... I can say that there is an excellent outcome - the learning opportunities to both teachers and students. Teachers learn from each other - from planning to execution including their teaching tactics. We helped each other from planning to implementation, to revision. Unlike before that I worked in isolation with the mere resources in my school - I plan, I implement, I evaluate and revise my own work. I think, this is the beauty of lesson study-the culture of oneness among teachers and schools..."

Teacher B: “... Sharing and cooperation among members of the Lesson Study are developed especially in terms of resources and equipment in science. (You know) not all schools have good resources and equipment in science. The $R L$ is developed collaboratively by the memberteachers. Revision is too vital in refining it (RL). The output is good as it is a product of our officious revision and try-out. I can say that the plan is good as we have planned and tried it out well..."

Teacher B explicated well the developed collaboration by the member teachers of the LS group. Moreover, both teacher B and A categorically mentioned the act of sharing their resources to the member teachers. It can be construed that the conducted LS resulted to excellent outcomes especially on the learning opportunities to both teachers and students. It could be noted that LS resulted positive outcomes as documented by the different countries that implemented it. Previous studies [5], [6], [24] categorically claimed that teacher's growth in content knowledge and reforms in practice are learned in bringing teachers together. This collaboration engages reciprocal exchanges of knowledge among their collaborators as mentioned by teachers A and B. In the current study, this act of bringing teachers together is paramount to a retooling program as most of them are not academically prepared to teach the subjects that they are teaching.

\subsection{Crafting teachers' competence through synergism}

Synergism plays a vital role in every group project. Through it, teachers will come to an opportunity of co-existing with each other as team players and not as competitors; hence, they learn the culture of accountability and the sense of belongingness. This replaced the old trait of kanya-kanya system which they observed in the past years because of extensive academic competitions between and among schools in the division. The kanya-kanya system is a practice where teachers plan, execute, and evaluate their own lesson plans which they will reuse in the years to come based on the perceived effectiveness by the teacher himself. 
In the implementation of LS in a DepEd-Division, Philippines, collaboration is used as a potent strategy to implement the curriculum in a bar-none standard as teachers collaborate with each other through functional groups. The importance of dialogue and interaction is underscored which supports the idea that learners in groups have the ability to organize and guide their learning activities. Furthermore, learners come to a learning progression in a shared-learning condition under social constructivism [1], [16], [25], [26].

Purportedly, teachers as life-long learners interact professionally and synergistically with other teachers to generate learning plans. This plan is derived from a multi-voice and multi-perspective approach in learning that is inherent in a dialogue and interactions with others through social reconstruction. This interaction scaffolds teachers' knowledge, skills, and beliefs towards the subject. Aptly, this is vital as most of them are not specialized to a specific field in science that they are teaching.

In the cases of the other countries that implemented LS prior to the Philippines, it was pointed out that the core of the LS is the collaborative lesson planning from a group of teachers with similar interests under a supervision of a senior teacher. This practice is believed to produce instructional improvement as it drives student learning which serve as basis for indirect learning by the teachers implementing it [3], [26], [27]. In the Philippines, particularly in a DepEd-Division, professors from a State University served as the KOs among the teacher-implementers. These KOs who served as critics revitalized the planning session and the revision of the plan. These concordances bring the teacher-implementers in a community of inquiry as their knowledge are developed holistically within a community of inquiry and practice [15], [16], [28]-[32].

The following transcripts from the informants manifest a culture of collaboration among them in their stride of implementing LS.

Teacher A: “... I can say that there is an excellent outcome - the learning opportunities to both teachers and students. Teachers learn from each other - from planning to execution including their teaching tactics. We helped each other from planning to implementation to revision. Unlike before that I worked in isolation with our mere resources - I plan, I implement, I evaluate and revise my own work. I think, this is the beauty of lesson study-the culture of oneness among teachers and schools..."

Teacher B: “... Sharing and cooperation among members of the Lesson Study are developed especially in terms of resources and equipment in science. (You know) not all schools have good resources and equipment in science. The RL is developed collaboratively by the memberteachers. Revision is too vital in refining it $(R L)$. The output is good as it is a product of our officious revision and try-out. I can say that the plan is good as we have planned and tried it out well..."

Teacher C: "...The quality of the lesson is improved from the observed qualities during the trial-implementations. We see some misconceptions, lengthy and repetitive activities, erroneous activities, and wrong directions. As we implement it, we enriched the plan by incorporating more appropriate measures. The courses of actions that we implement (teachers and head teachers in science) are effective because we plan as one together with our Knowledgeable Others (KOs) from a state university. I feel like we are one..."

Teacher D: “...Weaknesses and inadequacies of the original plan are seen and corrected. Likewise, the plan (research lesson) is enriched by fortifying it with appropriate activities. At times, we draw some inappropriate activities, procedures, among others, but they are corrected as we implement it. It was good as there was sense of ownership among all the members of the group. It is as if we are just one working hand-in-hand towards a common goal. Superb..."

Teacher E: “...I realized that we lack some knowledge in lesson planning. I realized our errors - from our misconceptions, the erroneous directions and procedures, and lengthy activities. It widens my knowledge through collaboration - teacher-implementers collaborate as we share our knowledge on the subject matter. It is not our field of specialization (although we are science teachers); so, we learn from every encounter..."

Teacher F: “...Through collaboration, non-majors will now be able to develop and deliver the lesson better..."

Teacher G: “...it makes learning more meaningful and interesting. Learners are made to think. It is good to see the cooperation of every teacher although they come from different schools..."

The synergy from the collaboration of the teacher-implementers led to the oneness of the group from working in isolation to working as a functional group towards one purpose. The claim of teacher $G$ explicated well the cooperation of every teacher although they come in different schools. The output of the group became an integral material on their claimed efficiency in teaching the subject as claimed by teachers 
$\mathrm{A}, \mathrm{B}, \mathrm{C}$, and D. Teachers $\mathrm{E}$ and $\mathrm{F}$ categorically claimed that non-majors came to be prepared in teaching various areas of science outside their specialization through their learning encounters in the LS sessions. Moreover, teacher $\mathrm{G}$ claimed that learners are made to think because of the meaningful and interesting plan.

The foregoing claims are found to be similar with those of studies [2], [7], [16], [25], [33]. Mon, Dali, and Sam [25] claimed the LS made Malaysian-implementers to become reflective and keener in promoting students to become active and participative in the planned lesson. Moreover, Butun [7] cited the case of Turkey's LS in transforming teachers to be more active in making students to think. These concordances of Butun [7], Ebaeguin and Stephens [16] aroused teacher-implementers to be more enthusiastic to be more focused in learning than in teaching: all because of their encounters in the LS group [25], [33].

\subsection{Boosting teachers' morale and confidence}

As teacher-implementers come to a culture of oneness in a culture of inquiry and practice through collaboration, they develop a niche to further enrich their knowledge that boost their morale and confidence to develop every lesson which is beyond their academic preparations. It can be noted that one of the facets of LS is an avenue for indirect learning by the teachers as teaching is claimed to be a cultural activity [24], [32], [34], [35]. Furthermore, LS in the framework of educational standpoint is geared towards the development of a shared professional culture and not just a professional development activity [3], [15], [33], [36]. Purportedly, professional development programs like LS enables the development of progressive traits of teacher that will hone their efficacy as classroom facilitators. In the Philippines, science teachers need continuous professional development activities that will sharpen their professional know-how towards the subject matter as many of them are non-majors. It may be noted that the current curricular framework uses the Spiral Curriculum which changed its plots per year level, i.e., science per year level integrates Earth Science, Biology, Chemistry, and Physics unlike the previous plot which offered specialized fields.

Despite the fact that some science teachers are non-majors to the science subjects that they are teaching, it is broad as the day-light that they gained morale and confidence from their experiences in the LS. This is evident in the following transcripts:

Teacher B: “...I feel more confident as the plan $(R L)$ is revised for how many times with the other members of the group and KOs. Although this is not my major, I am (now) confident that I can teach it well unlike before that I am very much perplexed that I may commit misconceptions despite the number of occasions of reading it from the book as this is not my specialization although I am a science teacher. Likewise, I was just alone in planning before..."

Teacher E: “...It diminishes my anxieties in teaching the subject because I am sure (now) that I got the correct notion and knowledge as the plan $(R L)$ is a product of the academic encounter of a group of teachers in the field together with the Head Teachers and Knowledgeable Others. We now collaborate unlike before - you know it for sure (...smiles...). This is not my major but I feel more confident now - the academic exchange of ideas is healthy for us..."

Coenders and N. Verhoef [9]; Ono and Ferreira [30] pointed out that LS brings the implements a new view in teaching their lessons. The shared experiences of the collaborators during the development phase made them think and feel competitive in teaching. In the same manner, teachers B and E developed similar feelings and line of thinking after undergoing the designed LS in their area. The presence of the MKOs in the current study made the teacher-implementers to develop confidence that boosted their morale although some of the subjects that they are teaching are beyond their specialization.

\subsection{Refining the quality of the research lesson}

The LS implementation in the locale of the study offers a wide range of opportunities for the teacher-implementers to look back on their instructional planning activities - from their kanya-kanya system to a Research Lesson Study which is an output of their FGD sessions with their counterparts among their neighboring schools and KOs. Let it be noted that LS covers activities where teacher-implementers can see the curriculum, lesson plan, instructional materials, and content in a more focused learning session. Teachers involved in this LS research collaboratively plan a lesson, implement it, and discuss the observed results in a debriefing session: all in a pursuit of improving the plan and the learning climate to be offered among student-learners [3], [15], [32], [37].

In this study, the teacher-implementers realized the beauty of LS particularly on polishing the RL. The benefits of its implementation are found beneficial as evidenced in the following transcripts: 
Teacher H: “...The RL and LS in general, is effective. Here, we fine-tune our plan $(R L)$. We saw some questions, directions, and activities that are tricky (if not, they are erroneous because of the misconceptions). So, activities contained in the plan are refined - they become fitted to the needs of lesson. This ensures that the plan is correct when we implement it in our own school..."

Teacher B: “...The conduct of LS minimizes or eliminates the misconceptions of teachers: we dissect concepts, coverage of the lesson, as well as the activities to be conducted to further optimize the teaching-learning conditions. The plan fits the scope within the time frame..."

"...I feel more confident as the plan (RL) is revised for how many times with the other members of the group and KOs. Although this is not my major, I am (now) confident that I can teach it well unlike before that I am very much perplexed that I may commit misconceptions despite the number of occasions of reading it from the book as this is not my specialization although I am a science teacher. Likewise, I was just alone in planning before..."

Teacher I: "...The RL is well-planned because of the revisions - the observations we had during the trial-implementations were incorporated in the final plan. The plan (RL) is implemented superbly as we implement and revise based on the observations that we had in the trial-implementation..."

Teacher D: “...Weaknesses and shortcomings of the original plan are seen and corrected. Likewise, the plan (RL) is enriched by fortifying it with appropriate activities. At times, we draw some inappropriate activities, procedures, among others, but it is corrected as we implement it. It was good as there was a sense of ownership among all the members of the group. It is as if we are just one working hand-in-hand towards a common goal. Superb..."

Teacher J: "... The sharings of our co-collaborators are very important. It improves the plan. It is also beneficial to the students because the lesson is well-planned. It eliminates wrong notions through collaborative focus discussions..."

Refinement of the LS is always wanting as collaborators come with new pedagogies and perspective of teaching and learning: content is checked, strategies are heightened, and students' learning is optimized. Boonsena, et al. [29] claimed that the designed lessons are made efficacious in meeting the expectations of every student in a higher mechanism. Can [8] and Royce [31] claim that the teacher-implementers improved their knowledge on instructional strategies and assessment components. Similarly, teacher B and J explicated that the LS is beneficial to the students due to the optimized teaching-and-learning activities. Teachers D, H, and I came to realize that the lesson is fortified with activities that promote better learning outcomes [8], [31], [33].

\subsection{Scheming avenues for critical thinking}

Lesson Studies are modelled to produce learners in a practiced community of inquiries as teachers are tasked to collectively research and plan a lesson for the purposes of improving instructional practices in observable norms and practices [5], [6], [37], [38]. Purportedly, this practiced community of inquiry holds the following tenets as measures of inquiry-based science teaching effectiveness [8], [12], [26], [28]: 1) It boosts the school science learning procedures in terms of students' activeness, learning motivation, and engagement in scientific investigations; 2) It improves the process skills of the student-learners, i.e., observing, measuring, classifying, interpreting, data analysis, experimenting, and communicating; and 3) It improves observable qualitative behavior and attitude of students towards the subject.

The collective planning and implementation of the LS develop better plans that come from a collegial scrutiny and educational comments from the group. The community of inquiry is practiced through a range of strategies from the teacher-implementers that stems to observable and practiced norms from the student-learners. Student-learners come to thinking sessions in a structured inquiry lesson as they get engaged with the structured problems and other avenues for learning in the developed RL [3], [23], [26], [31], [39], [40].

The following transcripts exude that LS improves the employment of critical thinking to classroom lessons through meaningful and interesting activities:

Teacher F: “...Lesson study provides more avenues for critical thinking through activities - the proper pacing and implementation are added factors contributing to its success. So, students are transformed to become thinkers because of these meaningful activities..."

Teacher G: “...it makes learning more meaningful and interesting. Learners are made to think. It is good to see the cooperation of every teacher although they come from different schools..." 
Teacher A: “...I believe that the students are more participative now. Activities are made interesting that requires keen and thorough analysis..."

Teacher I: “...Yeah! I must submit that LS brings the best among students. Activities are carefully planned by the team. This is imperative to better sessions that require wider sense of understanding. They are really made to think..."

Engaging classroom tactics are always wanting in the spirit of a learner-centered teaching and learning. Teachers A, G, F, and I believed that learners in the implemented LS are made thinkers, participative, keener, and analytical due to the activities that they are exposed with. Similar phenomenon is observed by various authors who implemented LS [1], [6], [7], [13], [14], [25]. Iksan, Zakaria, and Daud [1] emphasized the role of social interaction, while Butun [7], Bayram and Canaran [13] suggested that teachers should come with a tangible research plan addressing the observed strengths and weaknesses of LS in their research locale. The current study also recommends that teacher-implementers may come up with collaborative research activities on the effects of LS on the academic achievement and performances of students, as well as their experiences in their respective classes. Documentation of the success stories along this line may also be conducted among those who have implemented it since it was pilot tested in the division in 2017.

\section{CONCLUSION}

Based on the findings of the gathered data from the informants' interview, it can be concluded that LS develops culture of oneness, crafts teachers' competence through synergism, boosts teachers' morale and confidence, and refines the quality of the lesson plan of science teachers, as well as schemes avenues for critical thinking for student-learners. Lesson Study bridged the gap between the teachers' academic preparation and the subjects they are teaching because of the implementation of K-12 program in the basic education. As evidenced in this study, the informants are teaching subjects which are beyond their academic preparations. Henceforth, the employment of this CPD program among the teachers in the locale of the study bridged the gap on their academic shortcomings through the provisions of the LS implementation.

Moreover, the Knowledgeable Others from State Universities and Colleges played an important role in ensuring the success of the Lesson Study especially that the teachers are non-majors to the subjects that they were teaching. The Philippine version of K-12 program particularly in secondary science offers integrated science taught by non-majors, i.e., every year level has physics, chemistry, biology, and earth science. The burden is shared by all since they are teaching topics beyond their academic preparation, i.e., a biology major is teaching chemistry, physics, and earth science, and vice versa. Their indulgence in this CPD program will surely revitalize the informants' academic concordances due to their inability to formulate theoretical and laboratory concepts as they are not authorities in the subjects that they are teaching. Aptly, LS as evidenced in this study as a potential educational program is remarkable in reshaping the schematic knowledge and competence of the teacher-informants in areas that they are not authorities enjoining practices that solicit collaborative acts among them through coaching and modelling.

\section{REFERENCES}

[1] Z. Iksan, E. Zakaria, and Md. Daud, "Model of lesson study approach during micro teaching," International Education Studies, vol. 7, no. 13, pp. 253-260, 2014, doi: 10.5539/ies.v7n13p253.

[2] M.L. Wahman, A. Peplow, R. Kumar, and B. Refaei, "Benefits of using lesson study for scholarship of teaching and learning," International Journal for the Scholarship of Teaching and Learning, vol. 14, no. 1, pp. 1-6, 2020, doi: 10.20429/ijsotl.2020.140102.

[3] B. Doig and S. Groves, "Japanese lesson study: teacher professional development through communities of inquiry," Mathematics Teacher Education and Development, vol. 13, no. 1, pp. 11-93, 2011.

[4] E. Saito, "Key issues of lesson study in Japan and the United States: A literature review," Professional Development in Education, vol. 38, no. 5, pp. 777-789, 2012, doi: 10.1080/19415257.2012.668857.

[5] J. Myers, "The effects of lesson study on classroom observations and perceptions of lesson effectiveness," The Journal of Effective Teaching, vol. 12, no. 3, pp. 94-104, 2012.

[6] E. A. Burroughs and J. L. Luebeck, "Pre-service teachers in mathematics lesson study," The Montana Mathematics Enthusiast, vol. 7, no. 3, pp. 391-400, 2010.

[7] M. Butun, "Mathematics teachers' early lesson study experiences in Turkey: Challenges and advantages," World Journal of Education, vol. 9, no. 5, pp. 51-62, 2019, doi: 10.5430/wje.v9n5p51.

[8] H. Can, "Learning science teaching by taking advantages of lesson study: An effective form of professional development," Journal of Educational Issues, vol. 5, no. 2, pp. 150-169, 2019, doi: 10.5296/jei.v5i2.15497.

[9] F. Coenders and N. Verhoef, "Lesson study: Professional Development for beginning and experienced teachers," Professional Development in Education, vol. 45, no. 2, pp. 217-230, 2019, doi: 10.1080/19415257.2018.1430050. 
[10] T. Fujii, "Implementing Japanese lesson study in foreign countries: Misconceptions revealed," Mathematics Teacher Education and Development, vol. 16, no. 1, pp. 65-83, 2014

[11] G. Zhou, J. Xu, and D. Martinovic, "Developing pre-service teachers' capacity in teaching science with technology through microteaching lesson study approach," EURASIA Journal of Mathematics, Science and Technology Education, vol. 13, no. 1, pp. 85-103, 2017, doi: 10.12973/eurasia.2017.00605a.

[12] A. Ogegbo, E. Gaigher, and T. Salagaram, "Benefits and challenges of lesson study: A case of teaching physical science in South Africa," South African Journal of Education, vol. 39, no. 1, pp. 1-9, 2019, doi: 10.15700/saje.v39n1a1680.

[13] I. Bayram and O. Canaran, "An investigation of Turkish novice EFL teachers' perceptions of lesson study," International Journal of Curriculum and Instruction, vol. 11, no. 1, pp. 172-189, 2019.

[14] A. Ozdemir, "Implementation of the lesson study as a tool to improve students' learning and professional development of teachers," Participatory Educational Research, vol. 6, no. 1, pp. 36-53, 2019.

[15] M. Ebaeguin, "Designing Japanese lesson study as a teacher professional development program in a Philippine setting: Cultural considerations, challenges, and opportunities," Journal of the International Society for Design and Development Education, vol. 3, no. 11, pp. 1-15, 2019.

[16] M. Ebaeguin and M. Stephens, "Cultural challenges in adapting lesson study to a Philippines setting," Mathematics Teacher Education and Development, vol. 16, no. 1, pp. 1-25, 2014.

[17] L. Hoshmand, "Narratology, cultural psychology, and counselling research," Journal of Counselling Psychology, vol. 52, no. 2, pp. 178-186, 2005, doi: 10.1037/0022-0167.52.2.178.

[18] L. Leung, "Validity, reliability, and generalizability in Qualitative Research," Research and Audit, vol. 4, no. 3, pp. 324-327, 2015, doi: 10.4103/2249-4863.161306.

[19] K. Malterud, "Qualitative research: Standards, challenges, and guidelines," The Lancet, vol. 358, no. 9280, pp. 483-488, 2001, doi: 10.1016/S0140-6736(01)05627-6.

[20] C. Houghton, K. Murphy, B. Meehan, J. Thomas, D. Brooker, and D. Casey, "From screening to synthesis: Using NVIVO to enhance transparency in qualitative evidence synthesis," Journal of Clinical Nursing, vol. 26, no. 5-6, pp. 873-881, 2016, doi: 10.1111/jocn.13443.

[21] C. Zamawe, "The implications of using NVIVO software in qualitative data analysis: Evidence-based Reflections," Malawi Medical Journal, vol. 27, no. 1, pp. 13-15, 2015, doi :10.4314/mmj.v27i1.4.

[22] L. Nowell, J. Norris, D. White, and N. Moules, "Thematic analysis: Striving to meet the trustworthiness criteria," International Journal of Qualitative Methods, vol. 16, no.1, pp. 248-258, doi: 10.1177/1609406917733847.

[23] M. R. S. Arani, F. Keisuke, and J.P. Lassegard, “"Lesson Study" as professional culture in Japanese Schools: A historical perspective on elementary classroom practices," Japan Review, vol. 22, pp. 171-200, 2010.

[24] K.H. Chenault, "Building collaborative pedagogy: Lesson study in higher education," College Quarterly, vol. 20, no. 1, pp. 1-23, 2017.

[25] C.C. Mon, M.H. Dali, and L.C. Sam, "Implementation of lesson study as an innovative professional development model among Malaysian school teachers," Malaysian Journal of Learning and Instruction, vol. 13, pp. 82-111, 2016.

[26] Z. Yakar and D. Turgut, "Effectiveness of Lesson study approach on preservice science teachers' beliefs," International Education Studies, vol. 10, no. 6, pp. 36-43, 2017, doi: 10.5539/ies.v10n6p36.

[27] S. Asari, N. Fauziyah, and S. Uchtiawati, "Improving teacher pedagogic competencies in remote areas through lesson study activity," International Journal of Education and Literacy Studies, vol. 6, no. 2, pp. 53-62, 2018, doi: 10.7575/aiac.ijels.v.6n.2p.53

[28] A. Espinosa, J. Datukan, B. Butron, and AD. Tameta, "Perception of pre-service chemistry teachers on the utilization of productive lesson study as a framework of teaching and learning," International Journal for the Scholarship of Teaching and Learning, vol. 12, no. 1, pp. 1-7, 2018, doi: 10.20429/ijsotl.2018.120109.

[29] N. Boonsena, M. Inprasitha, N. Changsri, and G. Matney, "Teachers learning about teaching practice in a modifiy lesson study," Psychology, vol. 10, no. 7, pp. 977-988, 2019 doi: 10.4236/psych.2019.107064.

[30] Y. Ono and J. Ferreira, "A case study of continuing teacher professional development through lesson study in South Africa," South African Journal of Education, vol. 30, no. 1, pp. 59-74, 2010.

[31] C. Royce, "A revolutionary model of professional development," Science Scope, vol. 34, no. 3, p. 6, 2010.

[32] O. Zaslavsky, O. Chapman, and R. Lieken, "Professional development of mathematics teachers: trends and tasks," in A.J. Bishop, M.A. Clements, C. Keitel, J. Kilpatrick, F.K.S. Leung, eds., Second International Handbook of Mathematics Education, 2003, pp. 887-917.

[33] K. Abu-Alghayth, P. Jones, D. Pace-Phillips, and R. Meyers, "Through the looking glass: Lesson study in a center school," International Journal of Educational Methodology, vol. 6, no. 2, pp. 423-433, 2020, doi: 10.12973/ijem.6.2.423.

[34] T. Kadron and M. Inprasitha, "Professional development of mathematics teachers with lesson study and open approach: The process of changing teachers values about teaching mathematics," Psychology, vol. 4, no. 2, pp. 101-105, 2013, doi: 10.4236/psych.2013.42014.

[35] E. Kanellopoulou and M. Darra, "The planning of teaching in the context of lesson study: Research findings," International Education Studies, vol. 11, no. 2, pp. 67-82, 2018, doi: 10.5539/ies.v11n2p67.

[36] E. Giannakidou, K. Gioftsali, and E. Tziora, "The reflective act of the prospective teachers in applying a customized version of the Lesson Study model," Hellenic Journal of Research in Education, vol. 1, no. 1, pp. 27-55, 2013, doi: 10.12681/hjre.8791. 
[37] A. Takahashi, "The role of the knowledgeable other in lesson study: Examining the final comments of experienced lesson study practitioners," Mathematics Teacher Education and Development, vol. 16, no. 1, pp. 26-41, 2014.

[38] C. Yarema, "Mathematic teachers' views of accountability testing revealed through lesson study," Mathematics Teacher Education and Development, vol. 12, no. 1, pp. 3-18, 2010.

[39] W. Nashruddin and D. Nurrachman, "The implementation of lesson study in English language learning: A case study,” Dinamika Ilmu, vol. 16, no. 2, pp. 169-179, 2016.

[40] E. Duez, "Global applications of the Japanese lesson study in teacher education and training model," International Dialogues on Education, vol. 5, no. 1, pp. 65-73, 2018. 